\title{
EXPERT Cracking the Toll-like receptor code in fungal infections
}

Expert Rev. Anti Infect. Ther. 8(10), 1121-1137 (2010)

\section{Cristina Cunha', Luigina Romani ${ }^{1}$ and Agostinho Carvalho ${ }^{+1,2}$}

${ }^{1}$ Microbiology Section, Department of Experimental Medicine and Biochemical Sciences, University of Perugia, Via del Giochetto, 06126 Perugia, Italy

${ }^{2}$ Life and Health Sciences Research Institute (ICVS), School of Health Sciences, University of Minho, Campus de Gualtar, 4710-057 Braga, Portugal ${ }^{\dagger}$ Author for correspondence:

Tel.: +39075 5857498

Fax: +39075 5857411

aacarvalho2008@gmail.com

Innate control of fungal infection requires the specific recognition of invariant fungal molecular structures by a variety of innate immune receptors, including Toll-like receptors. In addition to the role in inducing protective immune responses, Toll-like receptor engagement may paradoxically favor fungal infections, by inducing inflammatory pathology and impairing antifungal immunity. Although the dissection of complex genetic traits modulating susceptibility to fungal infections is complex, the contribution of host genetics may hold the key to elucidating new risk factors for these severe, often fatal diseases. Understanding host-pathogen interactions at the innate immune interface will eventually lead to the development of new therapeutics and genetic markers in fungal infections.

\section{KeYwoRDs: fungal infections $\bullet$ genetic susceptibility $\bullet$ inflammation $\bullet$ innate immunity $\bullet$ Toll-like receptors}

The kingdom of fungi comprises a number of species that are associated with a wide spectrum of diseases in humans and animals, ranging from allergy and autoimmunity to life-threatening infections [1]. However, fungal infections, though disparate in nature, are relatively rare, so that few fungal species regularly cause disease in immunocompetent individuals. Other fungi are able to establish lifelong commensalism on human skin and body surfaces without necessarily causing disease [1]. This indicates that fungi, capable of colonizing almost every niche within the human body, must possess particular adaptation mechanisms of co-existence $[2,3]$, which deviate into overt disease under conditions of deregulated immune responses. In fact, most fungi causing disease in humans act as opportunistic pathogens in individuals with specific immune defects. Patients with phagocytic, cellular, combined and other primary immunodeficiencies, such as severe combined immunodeficiency, chronic mucocutaneous candidiasis (CMC), autoimmune polyendocrinopathy, candidiasis, ectodermal dystrophy, hyper-IgE syndrome, myeloperoxidase deficiency, leukocyte adhesion deficiency, DiGeorge syndrome, XL-EDA-ID (defects of NF- $\kappa B$ essential modifier), Wiskott-Aldrich syndrome and common variable immunodeficiency $[4,5]$, exhibit increased susceptibility to fungal infections. In addition, Candida species remain an important cause of hospital-acquired bloodstream infections, particularly in the setting of solid organ transplantation [6], whereas invasive aspergillosis (IA) is a leading cause of infection-related death in hematopoietic stem cell transplant (HSCT) recipients [7]. Clinically, severe fungal infections also occur in patients with immune reconstitution syndrome, an entity characterized by local and systemic reactions that have both beneficial and deleterious effects on infection [8]. These patients may experience intractable fungal infections despite the occurrence of pathogen-specific immunity.

Fungal diseases also include type I hypersensitivity, the most prevalent disease caused by airborne fungi, and a large number of other illnesses, including allergic bronchopulmonary mycoses, allergic chronic sinusitis, hypersensitivity pneumonitis and atopic eczema/dermatitis syndrome (formerly atopic dermatitis) [9]. Sensitization to molds has also been reported in patients with asthma and allergic bronchopulmonary aspergillosis (ABPA) is frequent in patients with asthma and cystic fibrosis [10]. Interestingly, there is evidence that fungal sensitization also contributes to autoreactivity against self-antigens due to shared epitopes with homologous fungal allergens [11].

The complex relationships of fungi with the vertebrate immune system are partly due to some prominent features. Among these, besides the genomic microvariation [12] to adapt to environmental abiotic stress conditions $[2,3]$, the ability to reversibly switch forms in infection may have resulted in an expanded repertoire of 
cross-regulatory and overlapping antifungal host responses at different body sites. Examples include the thermally dimorphic fungi (e.g., Histoplasma capsulatum and Paracoccidioides brasiliensis), which transform from saprophytic filamentous molds to unicellular yeasts in the host, the filamentous fungi (such as Aspergillus species) that, inhaled as unicellular conidia, may transform into a multicellular mycelium, and some species of Candida, capable of growing in different forms such as yeasts, blastospores, pseudohyphae and hyphae. Thus, in the context of the antagonistic relationships that characterize the host-fungus interactions, the strategies used by the host to limit fungal infectivity are necessarily disparate; in retaliation, fungi have developed their own elaborate tactics to evade or modulate host defenses and to survive [13,14]. However, because fungal diseases are rare, an unwavering host-fungus interface is a likely requisite for most, potentially pathogenic, fungi. This demands for a tight balance of pro- and anti-inflammatory signaling pathways at the host-fungus interface in order to achieve the two-component antifungal response that includes resistance, that is, the ability to limit fungal burden, and tolerance, for example, the ability to limit host damage caused by either the immune response or other mechanisms $[13,15,16]$.

In this article, we describe the current understanding on the contribution of innate immune receptors, such as Toll-like receptors (TLRs), to the achievement of the best-fitted host-fungus interaction. In addition, we will discuss the immune response to fungi as a genetically modulated event that may help to define the best individually tailored approaches to be integrated into new medical practices.

\section{The immune response to fungal infections}

Generation of a dominant Th1 response driven by IL-12 is essentially required for protective immunity against fungi (вох 1). Through the production of the signature cytokine IFN- $\gamma$ and the help granted by opsonizing antibodies, Th1 cells are instrumental in the optimal activation of phagocytes at sites of infection. Therefore, the failure to deliver activating signals to effector phagocytes may predispose patients to overwhelming infections, limit the therapeutic efficacy of antifungals and antibodies, and favor persistency and/or commensalism [13]. Immunological studies in patients with polar forms of paracoccidioidomycosis demonstrated an association between Th1-biased reactivity and the asymptomatic and mild forms of the infection, as opposed to the positive correlation of $\mathrm{Th} 2$ responses with the severity of the disease and poor prognosis [17].

IL- 4 acts as the most potent proximal signal for commitment to Th2 reactivity that dampens protective Th1 responses and favors fungal allergy. IL-4 may both deactivate and activate phagocytes and dendritic cells (DCs) for certain specialized functions; for instance, it may inhibit the antifungal effector activities of phagocytes, yet may promote IL-12 production by DCs [13]. However, susceptibility to fungal infections may not always be associated with an overt production of IL-4 [18]. Over the past several years, the demise of a Th1/Th2 dichotomy paradigm has been accompanied by a renaissance in probing the basic tenets of $\mathrm{CD}^{+}$ T-cell biology. As a result, instead of only two distinct 'fates' for developing $T$ cells, research has identified alternative fates and more flexibility in T-cell cytokine production than previously envisioned [19].

Th17 cells are now known to be a separate lineage of effector Th cells contributing to immune pathogenesis previously attributed to the Th1 lineage [20]. They produce a unique cytokine signature (IL-17, IL-17F, IL-21 and IL-22) and express transcription factors distinct from Th1 and Th2 cells. Naive mouse and human $C D 4^{+} \mathrm{T}$ cells activated in the presence of TGF- $\beta$ and IL- 6 express the transcription factor retinoid-related orphan receptor $\gamma \mathrm{t}$ and become Th17 cells that are stabilized by DC-derived IL-23 and amplified by IL-1 and IL-21. Several experimental studies and clinical investigations confirmed that IL-23-driven Th17 cells, rather than the Th1 cell subset, mediate the inflammatory responses of autoimmune or infectious origin [21,22]. In addition, both IL-23 and the Th17 pathway correlate with disease severity and immunopathology in diverse infections [23-25], suggesting that IL-12 and IL-23 have distinct roles in promoting antimicrobial immune responses and disease in vivo.

Th17 cells have an important function in the host defense response against extracellular pathogens, but they also have become notorious for their role in the pathogenesis of many autoimmune and allergic disorders. Emerging data on the mechanism by which Th17 cells induce tissue inflammation suggest that Th17 cells first infiltrate the site of tissue inflammation and then recruit other proinflammatory effector T cells (including Th1 cells) and innate cells (including neutrophils) to sites of tissue inflammation. As IL-17 receptors are widely expressed on parenchymal/tissue cells and IL-17 induces production of IL-1, IL-6, tumor necrosis factor (TNF), matrix metalloproteinases, IL-8 and chemokines, these mediators coordinate infiltration of other cell types to the site of inflammation and mediate massive tissue inflammation at the site where IL-17 is abundantly produced.

Th17 cells are induced in fungal infections through TLR- and non-TLR-dependent signaling [25-33]. Th17 are present in the human T-cell memory repertoire to Candida albicans [34,35] and Aspergillus fumigatus [36,37], and defective Th17 cell differentiation has been linked to CMC in patients with primary immunodeficiencies [38]. Although recent evidence support the importance of the Dectin-1/IL-17 axis in human mucocutaneous fungal infections [39], both positive and negative effects on immune resistance have been attributed to Th17 and IL-17 receptor (IL-17R) signaling in experimental fungal infections $[25,40,41]$. Thus, the role of IL-17 and Th17 cells in immunity versus pathology in fungal infections and diseases remains controversial [42]. The high susceptibility to systemic [41] and oral [40] candidiasis in conditions of defective IL-17RA signaling has been taken to indicate the essential role of IL-17RA signaling in host defense to Candida through the ability of IL-17 to mobilize neutrophils and induce $\beta$-defensin-3. However, exogenous IL-17 administration failed to rescue the Th17 deficiency and actually caused severe adverse reactions [40]. IL-17A was dispensable for protection in gastric candidiasis, and in fact neutralization of IL-17A greatly reduced fungal burden and ameliorated the systemic and gastrointestinal infections in IL-17RA-deficent mice. IL-17A was elevated 
in IL-17F-deficient mice and contributed to susceptibility to the infection in these mice, suggesting that IL-17F, by inhibiting IL-17A, may exert protective effects in candidiasis. However, the finding that IL-17A blockade increased resistance in IL-17F-deficient mice clearly indicated that neither cytokine is essential in infection [43]. It is likely that the protective versus disease-promoting effect of the IL-17/Th17 pathway may depend on the stage and site of infection, with early IL-17 able to exert some forms of antifungal resistance via IL-22 [43], defensins and neutrophils. On the other hand, the failure to downregulate microbe-induced expression of IL-17 could eventually be one major link connecting infection with chronic inflammation.

The mechanisms that have linked inflammation to chronic infection have been the offending potential of IL-17A that impeded the timely restriction of neutrophil inflammatory potential, preventing optimal protection to occur [44]. IL-17A also activated the inflammatory program of neutrophils by counteracting IFN- $\gamma$-dependent activation of indoleamine-2,3-dioxygenase (IDO), known to limit the inflammatory status of neutrophils, as well as by inducing the release of metalloproteinases and oxidants, which likely accounts for the high inflammatory pathology and tissue destruction associated with Th17 cell activation. Evidence indicates that the detrimental side effect of the inflammatory action of an unopposed IL-23/IL-17 pathway, which is under physiological conditions restrained by IDO, occurs through a mechanism leading to the sequential generation of regulatory and anti-inflammatory $\mathrm{V} \gamma 4^{+} \gamma \delta$ and $\mathrm{CD} 25^{+} \alpha \beta$ T cells [15]. This suggests that the intersection of $\gamma \delta$ cells (present in all vertebrates) with tryptophan catabolism (conserved through the past 600 million years of evolution) might represent a milestone in the evolution of the immune system, combining the innate and acquired immune systems in the proper control of infection [44].

These new findings provide a molecular connection between the failure to resolve inflammation and lack of antifungal immune resistance and point to strategies for immune therapy of fungal infections that attempt to limit inflammation to stimulate an effective immune response. More generally, the Th17 pathway could be involved in the immunopathogenesis of chronic fungal diseases where persistent fungal antigens may maintain immunological dysreactivity. In fact, IL-17 neutralization increased fungal clearance, ameliorated inflammatory pathology and restored protective Th1 antifungal resistance, a finding pointing to the therapeutic utility of immunomodulatory strategies aimed at reducing Th17-driven hyperinflammation in fungal infections [44].

Despite the excitement raised by the new findings, much remains to be learned, including the dependency of Th17 on the plasticity of human $\mathrm{CD}^{+}{ }^{+} \mathrm{T}$-cell differentiation and the relative contribution of the various populations of IL-17-producing cells to the pathogenesis of infections and diseases caused by the different fungi. In this regard, Th17 cells also produce IL-22, a member of the IL-10 family of cytokines, which has been shown to play a more important role than IL-17 in host defense in the lung and gut [45]. Recent findings suggest that the IL-23/IL-22/defensins pathway is crucially involved in the control of fungal growth at mucosal and nonmucosal sites, particularly in conditions of Th1 deficiency [43]. Thus, further tweaking the Th17 model, Th17 may exert its protective role in fungal infections through IL-22.

\section{Fungal sensing by the innate immune system}

The antigen-independent sensing of fungi by the innate immune system triggers a set of chronological events required for protection against the specific pathogen. Receptors on phagocytes not only mediate downstream intracellular events related to clearance, but also participate in complex and disparate functions related to immunomodulation and activation of immunity, depending on the cell type. Therefore, in order to achieve optimal activation of antigen-specific adaptive immunity, it is first necessary to activate the pathogen detection mechanisms of the innate immune system.

Toll-like receptors are pattern recognition receptors (PRRs) that participate in the mediation of microbial recognition and initiation of inflammatory and antimicrobial host defenses. TLRs are type I transmembrane proteins that share characteristic extracellular and cytoplasmic domains: a leucine-rich repeat extracellular domain responsible for the recognition of invariant microbial structures, the so-called pathogen-associated molecular patterns (PAMPs) (Table 1), and a cytoplasmic tail containing a highly conserved region, known as the Toll/IL-1 receptor (TIR) domain, responsible for transducing intracellular signals [46]. Upon ligand binding, TLRs recruit TIR domain-containing adapter proteins to the cytoplasmic portion of the TLRs through homophilic interaction of their TIR domains, inducing the activation of kinase cascades, ultimately leading to the activation of transcription factors such as NF- $\mathrm{KB}$ and the interferon regulatory factor family, which successively induce gene expression and production of various chemokines, cytokines and molecules required for antigen presentation or costimulation. Examples of the adapter molecules include MyD88 and TRIF [46]. The differential responses mediated by distinct TLR ligands can be explained in part by the selective usage of these adapter molecules. 


\section{Table 1. Pattern recognition receptors sensing fungal-associated molecular patterns.}

\begin{tabular}{|c|c|c|}
\hline PRR & PAMP & Ref. \\
\hline \multicolumn{3}{|l|}{ TLRs } \\
\hline TLR-2 & $\begin{array}{l}\text { Phospholipomannan } \\
\text { GXM }\end{array}$ & \\
\hline TLR-4 & $\begin{array}{l}\text { Mannan } \\
\text { O-linked mannosil residues } \\
\text { GXM }\end{array}$ & \\
\hline TLR-9 & CpG oligodeoxynucleotides & [111-113] \\
\hline \multicolumn{3}{|l|}{ CLRs } \\
\hline MR & $\begin{array}{l}\text { Mannan } \\
N \text {-linked mannosil residues }\end{array}$ & \\
\hline Dectin-1 & $\beta$-(1,3)-glucan & {$[57,120]$} \\
\hline Dectin-2 & High mannose structures $\left(\operatorname{Man}_{(9)} \operatorname{GlcNAc}_{(2)}\right)$ & [160] \\
\hline DC-SIGN & Mannose structures & {$[161]$} \\
\hline Galectin-3 & $\beta$-(1,2)-mannosides & [129] \\
\hline \multicolumn{3}{|l|}{ NLRs } \\
\hline NLRP3 & Unknown & {$[61,73]$} \\
\hline \multicolumn{3}{|c|}{$\begin{array}{l}\text { CLR: C-type lectin receptor; DC-SIGN: Dendritic cell-specific intracellular } \\
\text { adhesion molecule grabbing non-integrin; GXM: Glucuronoxylomannan; } \\
\text { MR: Mannose receptor; NLR: Nucleotide-binding domain leucine-rich repeat } \\
\text { containing receptor; PAMP: Pathogen-associated molecular pattern; } \\
\text { PRR: Pattern recognition receptor; TLR: Toll-like receptor. }\end{array}$} \\
\hline
\end{tabular}

TLRs are expressed in various cell types including, but not limited to, monocytes, macrophages, DCs and neutrophils, and can be predominantly present on the cell surface (TLR-1, -2, $-4,-5$ and -6 ) or retained intracellularly in endosomes (TLR-3, $-7,-8$ and -9$)$. Recent evidence also suggests an important contribution of TLRs to antimicrobial defense and immunosurveillance at epithelial surfaces [47-49]. Epithelial cells (ECs), no longer considered innocent bystanders [47], are now recognized as central participants in innate and adaptive immune responses as well as in mucosal inflammation and allergy [50]. Through the activation of TLRs by endogenous and exogenous ligands, ECs may play a central role in determining the balance between a state of 'mucosal homeostasis', as is required for optimal organ function, and 'mucosal injury', leading to mucosal inflammation and barrier breakdown [47]. In the case of fungi, respiratory ECs sense germinating conidia of $A$. fumigatus through MyD88-dependent and -independent pathways [51]. In this regard, we have recently found that ECs contribute to antifungal immunity by providing protective tolerance through a TLR-3/TRIF-dependent pathway converging on IDO, a key regulator of the Th1/Treg versus Th17 balance in aspergillosis [49]. Similarly, ECs actively contribute to host resistance to C. albicans via immunological crosstalk with TLRs and neutrophils [48,52]. In addition to TLRs, other PRRs, including Dectin-1, may orchestrate the overall antifungal response at epithelial surfaces (see later).
Interaction of fungi with TLRs is nevertheless a complex process as, first, TLRs may function as homodimers or heterodimers (most notably TLR-2/TLR-1 and TLR-2/TLR-6) and may collaborate with other non-TLR PRRs in recognizing fungal ligands or in triggering intracellular signaling pathways. Second, expression of fungal ligands is different at the surface of fungal cells depending on the morphotype, a phenomenon that influences the type of host immune response induced. Therefore, the different impact of TLRs on innate and adaptive immunity is consistent with the ability of each individual receptor to activate specialized antifungal effector functions on innate immune cells, such as the respiratory burst, degranulation, and production of chemokines and cytokines [33-55]. Although the signaling pathways elicited by TLRs are known to be essential in controlling fungal infection [56], recent studies have also highlighted the pivotal role of C-type lectin receptors (CLRs), most notably Dectin-1, as the prototype of the innate non-TLR signaling pathway for antifungal sensing [57]. Dectin-1 is a myeloid-expressed transmembrane receptor that specifically recognizes the cell wall carbohydrate $\beta-(1,3)$-glucan of many fungi [58-60]. The cytoplasmic tail of the receptor contains an immunoreceptor tyrosine-based activation-like motif related to those of adaptive antigen receptors, which can mediate myeloid cell activation, cytokine production and a variety of antifungal responses either through the spleen tyrosine kinase Syk/cytoplasmic caspase recruiting domain 9 (CARD9) [28,61] or Raf-1 [62] pathways. As for TLRs, avoiding recognition by Dectin-1 could be a counterstrategy of fungi for immune evasion $[63,64]$. The finding that human Dectin-1 deficiency has been associated with mucosal, but not invasive, Candida infections [39,65] suggests that Dectin-1 function may also be crucial to EC-mediated protection in mucosal candidiasis. In this regard, Dectin-1 has been shown to have an inducible expression in ECs [66]. However, given the ability of Dectin-1 signaling to activate canonical and noncanonical NF- $\kappa$ B pathways [62], known to have distinct, yet complementary roles in immunity and tolerance to fungi [67-69], this would predict additional and unexpected Dectin-1 functions in antifungal immunity and immunosurveillance at mucosal surfaces.

A number of fungal cell wall components may act through several distinct PRRs, each activating specific antifungal programs on phagocytes and DCs $[13,56,70,71]$ but cooperating for immune cell activation [54]. The environmental set-up also probably affects PRR function, given that the optimal ability of cells to phagocytose fungi is observed in the environment where a pathogen is naturally encountered [72]. However, another function of innate immunity that is emerging is its role in sterile inflammation - that is, inflammation caused by endogenous ligands. In this regard, implicated in fungal sensing are also nucleotide-binding domain leucine-rich repeat containing receptors (NLRs) that sense nonmicrobial danger signals - that is, xenocompounds or molecules that when recognized alert the immune system of hazardous environments, perhaps independently of a microbial trigger and form large cytoplasmic complexes called inflammasomes, most notably NLRP3, which link the sensing of fungal products and metabolic stress to the activation of inflammatory caspases, such as caspase-1, and the secretion of bioactive IL-1 $\beta$ and IL-18 [73-75]. Consistently, Nlrp3-deficient mice are highly susceptible 
to systemic [75-77] and mucosal [76] candidiasis, and a genetic polymorphism in the human gene encoding for NLRP3 was correlated with impaired IL- $1 \beta$ production upon $C$. albicans stimulation of peripheral blood mononuclear cells and with increased frequency of recurrent vulvovaginal candidiasis in women with vulvar vestibulitis syndrome [78]. Although the precise mechanisms of NLRP3 activation by fungi are still far from being completely understood, it is known that cell priming is required, for example, through PRRs such as TLRs and CLRs, to initiate NF- $\kappa \mathrm{B}$-dependent transcriptional upregulation of NLRP3 [79]. Altogether, the current knowledge in the field highlights how TLR activation itself is a 'double-edged sword', as members of the TLR family are involved in the pathogenesis of autoimmune, chronic inflammatory disorders such as asthma, rheumatoid arthritis and infectious diseases. Thus, by hyperinducing proinflammatory cytokines, by facilitating tissue damage or by impairing protective immunity, TLRs might paradoxically promote the pathogenesis of infections [80]. Not surprisingly therefore, fungal pathogens are able to exploit PRR-based strategies to divert and subvert host immune responses to fungi [81].

\section{TLRs in fungal infections}

The initial observation that Toll-deficient Drosophila were unable to mount effective antifungal responses and were highly susceptible to $A$. fumigatus infection [82] led to the assumption that mammalian TLRs also participated in antifungal immunity. In fact, TLR-2, -4 and -9 signaling has been particularly demonstrated to contribute to host responses against fungi both in mice (reviewed in [71]) and in humans (Box 2) [83].

\section{$T L R-2$}

TLR-2 has been reported to recognize the phospholipomannan component of the Candida cell wall [84]. Although the first studies investigating TLR-2 function in antifungal host defense reported protection-associated consequences for TLR-2 signaling during infection [85,86], we found instead that TLR-2-deficient mice were more resistant to disseminated candidiasis, accompanied by a decreased production of IL-10, and increased IL-12 and INF- $\gamma$ production [56]. In line with our findings, TLR-2-deficient macrophages have been shown to have an enhanced capacity to contain C. albicans [87]. Moreover, a previously unanticipated role for TLR-2 in the replenishment of the innate immune system during infection, integrating signals from extrinsic pathogens with those from normal growth and differentiation factors, rather than a direct effect on the antifungal immune capacity, has been demonstrated in a recent study in which TLR-2/MyD88-mediated recognition of C. albicans by hematopoietic stem and progenitor cells induced differentiation into functional phagocytes, required for the rapid generation of innate immune cells in response to the fungus [88]. In addition, a restricted role for TLR-1, and especially TLR-6, known to form heterodimers with TLR-2, has been reported in C. albicans recognition, although animals genetically deficient in these receptors were not more susceptible to infection [89].

The consequences of the absence of TLR-2 in aspergillosis are more complex. Wang et al. reported no role for TLR-2 in the recognition of Aspergillus hyphae [90] and we also found that cyclophosphamide-treated TLR-2-deficient mice did not present an increased susceptibility to aspergillosis, although fungal burden in the lungs was increased [56]. This was associated with higher numbers of lung IL-4-producing $\mathrm{CD}^{+} \mathrm{T}$ cells but also with higher TNF levels [56]. These findings are nevertheless in contrast with those using a model of IA in mice immunosuppressed with vinblastine, in which TLR-2-deficient animals had higher mortality rates and significantly lower levels of lung TNF than wild-type mice [91].

The role of TLR-2 in the recognition of Cryptococcus neoformans is also not clear, with studies reporting that TLR-2 can bind cryptococcal glucuronoxylomannan [92] and mediate cytokine production in response to the fungus [93], whereas other authors found that TLR-2 was not involved in cryptococcal-induced cytokine production [94]. On the other hand, TLR-2 deficiency has recently been shown to promote chronic pulmonary infection by P. brasiliensis through the skewing towards a Th17 response associated with diminished expansion of Treg cells and increased lung pathology due to unrestrained inflammation [95]. In conclusion, TLR-2 seems to play a role in fungal infection, although disagreement persists regarding the precise components recognized and the amplitude of the effects.

\section{$T L R-4$}

TLR- 4 is perhaps the most extensively studied PRR; it has been reported to recognize mannans from Saccharomyces cerevisiae and C. albicans [96], as well as short linear $O$-bound mannans 
of C. albicans, able to induce proinflammatory cytokines [97]. The first experimental models reported that the absence of TLR-4-mediated signals resulted in increased susceptibility to disseminated candidiasis, together with decreased induction of chemokines and impaired neutrophil recruitment at the site of infection [85]. In line with these observations, we found that TLR-4-deficient mice mounted a defective Th1 protective immunity to the fungus in the face of an efficient innate antifungal resistance [56] and, more recently, absence of functional TLR-4 has been demonstrated to impair macrophage responses after C. albicans infection [98]. Furthermore, TLR-4 also seems to be important for adaptive immune responses induced by $C$. albicans [56]; in fact, stimulation of DCs by $C$. albicans was shown to induce TLR-4-dependent cytokine production including IFN- $\gamma$ and IL-12, resulting in protective Th1-mediated cellular responses [99].

A globally important role for TLR-4 and -2 in host defense against disseminated candidiasis was also demonstrated in part by the increased susceptibility of MyD88-deficient mice to C. albicans infection $[56,100]$. This adapter protein was shown to be involved in the induction of protective immune responses by DCs [56], as well as in phagocytosis, killing and cytokine production by Candida-infected cells [56,101]. In addition, we found that generation of protective immunity to $C$. albicans relies on the presence of functionally and phenotypically distinct Treg cell subsets that are sequentially induced in the course of infection through a process implicating distinct, nonredundant roles of MyD88 and TRIF pathways. Sensing of the fungus through both MyD88 and TRIF pathways mediates the induction of a state of protective tolerance, in which fungal persistence is maintained in the context of a poorly inflammatory environment. IDO, known to have a central role in the induction of Th1 immunity within a regulatory environment [102], appears to be involved in TRIF-dependent tolerance to the fungus.

A role for TLR-4 in the recognition of $A$. fumigatus was suggested for the first time by Wang et al. [90] and subsequent studies have shown that TLR- 4 is involved in signaling and cytokine production in response to Aspergillus [103]. These findings were supported by our own data showing that TLR-4-deficient mice had significantly lower survival rates, higher lung fungal burdens and higher numbers of IL-4-producing $\mathrm{CD}^{+} \mathrm{T}$ cells [56], together with an inability to effectively clear the fungus [70]. Interestingly, otherwise immunocompetent mice genetically deficient in TLR-2, TLR-4, IL-1R1 or MyD88 are not susceptible to IA [56,104,105]. Despite these findings, TLR signaling through MyD88 appears to be necessary for the early inflammatory responses to Aspergillus in immunocompetent hosts, since in the absence of MyD88, fewer natural killer cells and higher fungal burdens in the infected lung were observed early after the fungal challenge [106]. Furthermore, MyD88-mediated signaling was required for the subsequent activation of protective adaptive responses [56,107]. In this regard, it is also noteworthy that the absence of a negative regulator of TLR signaling, Toll IL-1R8 (TIR8), in immunocompetent mice challenged with Aspergillus was found to reduce survival rates and increase lung fungal growth that were associated with elevated lung IL-17 and IFN- $\gamma$ levels but lower IL-10 and Foxp3 transcript levels, suggesting that the absence of this regulatory process results in the detrimental activation of Th1 and Th17 immunity [104].

TLR-4 is also involved in susceptibility to Pneumocystis pneumonia, with severe impairment in cytokine production being displayed by alveolar macrophages derived from mice deficient in TLR-4 [108]. By contrast, the C. neoformans component glucuronoxylomannan binds to TLR-4 and leads to translocation of NF- $\kappa \mathrm{B}$, but not to induction of cytokine production [92], and these findings were supported by the fact that TLR- 4 does not play a major role in cryptococcal host defense [109]. More recently, TLR-4 signaling has been shown to promote severe paracoccidioidomycosis, an effect mediated by vigorous inflammatory reactions and impaired expansion of Treg cells [110].

Overall, TLR-4 appears to play a major role in controlling the balance between detrimental and protective immune responses to the fungus through its ability to both promote (via MyD88) and inhibit (via TRIF) Th17 development (Figure 1) [26]. This suggests that conditions of high-threat inflammation may represent a local environmental factor that predispose to Th17 activation in candidiasis or aspergillosis. IL-17-producing cells are induced by Candida or Aspergillus through innate signaling via Dectin-1/CARD9 [28] and TLR/MyD88 [25] and they are inhibited by negative regulators of TLRs [104] and TRIF [26]. Activation of pathogenic Th17 cells accounts for susceptibility to candidiasis and aspergillosis under conditions of deficient p35 [25], TRIF [26], TIR8/SIGIRR [104] or functional NADPH oxidase expression [15]. In all of these settings, Th17 pathway expression - rather than an unrestrained Th1 response - correlates directly with defective pathogen clearance, and failure to resolve inflammation as well as initiate protective responses to Candida and Aspergillus.

\section{TLR-9}

Unmethylated CpG sequences are the natural ligands for TLR-9 and several reports have now suggested that TLR-9 can recognize fungal DNA [111-113]. While no increased susceptibility of TLR-9deficient mice to disseminated candidiasis has been observed, these animals tended to have lower fungal burdens [56], as well as less IL-12 and more IL-10 and IL-4 than control mice [12]. It is unclear why this shift towards an anti-inflammatory cytokine profile, known to be deleterious for the anti-candidal host defense, did not result in a deleterious effect on the outcome of the infection. Interestingly, DNA from C. albicans was found to activate bone marrow-derived DCs (BM-DCs) through a TLR-9-mediated signaling pathway, nevertheless using a mechanism independent of the unmethylated $\mathrm{CpG}$ motif [111]. This suggests that multiple TLR-9-PAMP interactions may occur in C. albicans recognition in order to enable the immune system to respond to the fungus in a more sensitive and specific way [54]. There is no data on $\mathrm{CpG}$ DNA as an adjuvant in $C$. albicans vaccination models, although it has been shown to enhance Th1-induced protection against IA in mice vaccinated with recombinant Aspergillus proteins [114].

TLR-9 has been shown to initiate immune responses to Aspergillus through the recognition of fungal unmethylated $\mathrm{CpG}$ DNA in murine BM-DCs and human plasmacytoid DCs, resulting in the secretion of proinflammatory cytokines [113]. Surprisingly, 

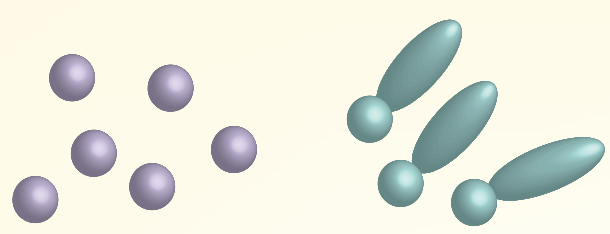

Aspergillus conidia

Candida hyphae
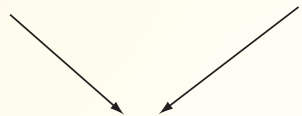

p38

canonical NF-kB<smiles>C1=CCCCC1</smiles>

IL-12

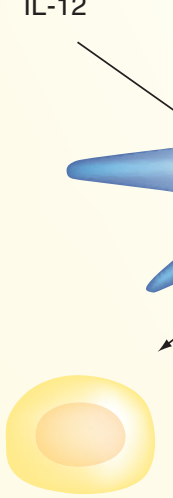

Th1

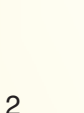

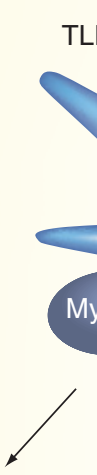
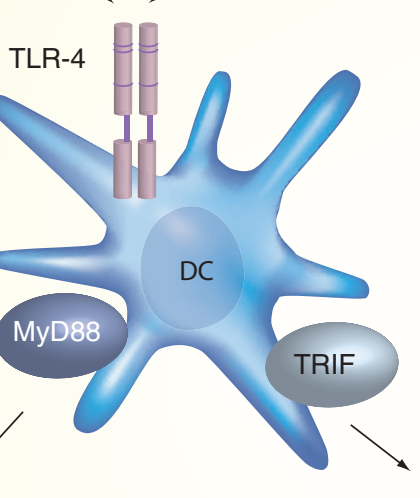

noncanonical NF-kB IDO
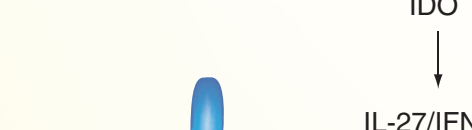

L-27/IFN- $\beta$

Figure 1. The activation of distinct signaling pathways downstream Toll-like receptors in murine dendritic cells translates the recognition of the fungus into protective Th1/Treg or inflammatory Th2/Th17 responses. Two alternative downstream signaling pathways are activated through TLR-4 in tolerogenic DCs: a MyD88-dependent pathway, which results in the activation of p38/ canonical NF- $\kappa B$, production of IL-12 and development of protective Th1 responses; or a TRIF-dependent pathway, which results in the production of IL-10 that, together with the activation of p38/STAT3/noncanonical NF- $\kappa \mathrm{B}$, leads to the activation of IDO and production of IL-27 and IFN- $\beta$, promoting Treg differentiation. In inflammatory DCs, the MyD88-dependent signaling occurring through TLR-2 is transduced through ERK, JNK, PI3K/Akt/mTOR and canonical NF- $\mathrm{B}$, leading to the production of either IL-10 and IL-4 and consequent nonprotective Th2 responses, or IL-23 and Th17 responses.

DC: Dendritic cell; IDO: Indoleamine 2,3-dioxygenase; NF: Nuclear factor; TLR: Toll-like receptor.

Data taken from $[67,68]$.

peritoneal neutrophils from TLR-9-deficient mice have a greater ability to kill Aspergillus conidia and hyphae [70], and TLR-9deficient mouse lung DCs produce less IL-12p70 and more IL-10 in response to conidia [56]. However, the role of TLR-9 in the context of in vivo defense against Aspergillus appears to be more complex. In the setting of immunosuppression or antibody-mediated 
neutrophil depletion, TLR-9-deficient mice survive longer and have significantly lower fungal burdens following challenges with Aspergillus conidia [56,70,115], suggesting the involvement of TLR-9 signaling in an immunoregulatory mechanism that ultimately benefits the fungus and may be mediated by neutrophils. In the context of airway hypersensitivity to Aspergillus, however, the absence of TLR-9 led to lower levels of methacholine-induced airway hyperreactivity but promoted fungal growth in the lung associated with reduced lung Dectin-1 expression levels; this is remarkable since wild-type mice sensitized to Aspergillus do not develop invasive disease following the administration of even large inocula in the setting of neutrophil depletion [116]. It remains to be established whether this effect is due to a failure of TLR-9-deficient mice to develop acquired immunity to Aspergillus during the sensitization or whether this finding is due to the absence of a TLR-9-mediated recognition of Aspergillus during the secondary challenge.

DNA from C. neoformans was also found to activate TLR-9, which was able to trigger IL-12p 40 and expression of CD40 upon stimulation in murine DCs [112]. In conclusion, most of the data available at this time suggests a role for TLR-9 in the recognition of fungal DNA, but the magnitude of this effect for the overall antifungal defense is likely to be overshadowed by redundant signals induced by other PRRs.

\section{Collaborative crosstalk between TLRs \& Dectin-1}

The first in vivo evidence that Dectin-1 plays an important role in innate fungal host defense was reported by a study showing that blocking Dectin-1 leads to increased $A$. fumigatus fungal burden in the lung [117]. Dectin-1-deficient mice are also more susceptible to infection with $C$. albicans, resulting in lower survival and increased fungal burdens [118]. However, another study using a different strain of mice deficient in Dectin-1 could not confirm this, but found an increased susceptibility to Pneumocystis infection [59]. Although it has been suggested that Dectin-1 is not likely essential for the development of host protective responses to C. neoformans [119], fungal spores were nevertheless found to be phagocytosed by alveolar macrophages via interactions between fungal $\beta$ - $(1,3)$-glucan and the host receptors Dectin- 1 and CD11b [120]. Accordingly, Dectin-1 has been suggested to play a pivotal role in $P$. brasiliensis recognition, internalization and consequent activation of the immune response against the fungus [121].

It has been demonstrated that infection with $C$. albicans induces CARD9-dependent Th17 cells [28], and that cytokine production induced by $C$. albicans by both human mononuclear cells and murine macrophages is dependent on Dectin-1 [122]. Although Dectin-1 signaling alone is sufficient to induce responses upon fungal recognition, several studies have emphasized that it is also able to cooperate with TLRs leading to synergistic proinflammatory responses. In fact, Dectin-1 has been shown to collaborate with TLR-2 to trigger proinflammatory responses to $C$. albicans and zymosan [123,124], and to amplify TLR-4-dependent pathways in a Syk-dependent manner [125]. In fact, evidence for an anti-inflammatory role of TLR-2 in antifungal host defense has been supported by a study reporting zymosan to induce DC tolerogenesis through a TLR-2- and Dectin-1-mediated pathway involving MAPK/ERK signaling [126]. Furthermore, Dectin-1 and TLR-2 also collaborate for the phagocytosis of Aspergillus conidia [127], and $A$. fumigatus can activate transcription through a Dectin-1/Syk-dependent pathway [128]. Overall, these findings suggest an important role for Dectin-1 in antifungal immunity, either directly or through collaborative signaling with TLR-2 and/or TLR-4.

In addition to Dectin-1, several interactions between TLRs and other PRRs are well documented. Galectin-3, a PRR which recognizes $\beta$ - $(1,2)$-mannosides, has recently been shown to associate with TLR-2, and this leads to the ability to discriminate between the pathogenic $C$. albicans and the nonpathogenic S. cerevisiae [129]. In addition, the TLR-2 pathway itself is able to inhibit TLR-4-mediated production of IL-12 through stabilization of the c-Fos transcription factor [130]. Another study demonstrated that when TLRs activate NF- $\mathrm{KB}, C$. albicans can induce DC-SIGN-dependent signals, which subsequently lead to acetylation of the NF- $\mathrm{B} B$ subunit $\mathrm{p} 65$ [131]. This results in prolonged and increased IL-10 production that shifts the proinflammatory response induced by TLRs to a more anti-inflammatory profile [131]. All these observations imply that the crosstalk between PRRs is essential to the complexity and flexibility of the innate immune response against fungi.

\section{Genetic variability of PRRs \& human susceptibility to fungal infection}

There is now undeniable evidence that genetic variants within recognition molecules involved in innate immunity may account, in part, for the inherited differences in human susceptibility to infection [132]. Given the broad effect of TLRs on immunity [46], their function in human disease, and specifically in fungal infections, has been investigated largely by comparing the incidence of disease among individuals with different polymorphisms in genes that participate in TLR signaling (TaвLe 2). Accordingly, growing amounts of data suggest that the ability of certain individuals to properly respond to TLR ligands may be impaired by polymorphisms in TLR genes, resulting in an altered susceptibility to, or course of, infectious or inflammatory disease [133]. Most studies so far have focused on the highly polymorphic TLR-4 gene, in which two co-segregated missense polymorphisms - D299G and T399I - have been described to compromise the extracellular ligand-binding domain of TLR-4 [134]. These variants have been linked with blunted airway [135] and systemic inflammatory responses [136] to inhaled lipopolysaccharide in adults and attenuated lipopolysaccharide-induced responses in primary airway ECs [135]. Interestingly, the D299G substitution was found to have a greater functional impact compared with the T399I genotype [135]. Figure 2 illustrates the role of genetic polymorphisms in PRRs in susceptibility to fungal infections and their associated functional consequences on the host's immune response to fungi.

The TLR-4 polymorphisms D299G and T399I have been shown to contribute to a higher risk of Candida bloodstream infection, supposedly through increased IL-10 production [137]. CMC patients were also reported to have increased IL-10 over IFN- $\gamma$ production, possibly occurring in association with 
Table 2. Human genetic association studies of polymorphisms in pattern recognition receptors and susceptibility to fungal infections.

\begin{tabular}{|c|c|c|c|c|}
\hline PRR & SNPS & SNP source & Study definition and sample size ${ }^{\dagger}$ & Ref. \\
\hline TLR-1 & R80T & $\mathrm{R}$ & IA $(n=22)$ versus no IA $(n=105)$ HSCT patients $(p=0.04)$ & {$[147]$} \\
\hline TLR-1/TLR-6 & N248S/S249P & $\mathrm{R}$ & IA $(n=22)$ versus no IA $(n=105)$ HSCT patients $(p=0.02)$ & {$[147]$} \\
\hline TLR-4 & D299G/T399l & & Candida BSI $(n=43)$ versus controls $(n=166 ; p<0.05)$ & [137] \\
\hline TLR-4 & D299G/T399| & & CCPA $(n=40)$ versus controls $(n=80 ; p=0.003)$ & [146] \\
\hline TLR-4 & D299G/T399| & D & $\begin{array}{l}\text { IA }(n=33) \text { versus no IA }(n=303) \text { HSCT patients (discovery study, } p=0.002) \\
\text { IA }(n=103) \text { versus no IA }(n=263) \text { HSCT patients (validation study, } p=0.02)\end{array}$ & [148] \\
\hline TLR-4 & D299G/T399| & D & $\begin{array}{l}\text { Aspergillus-colonized }(n=58) \text { versus noncolonized }(n=51) \text { HSCT } \\
\text { patients }(p=0.003) \\
\text { IA }(n=34) \text { versus no IA }(n=24) \text { among precolonized HSCT patients }(p=0.03)\end{array}$ & [145] \\
\hline TLR-9 & T-1237C & & ABPA $(n=22)$ versus controls $(n=80 ; p=0.043)$ & {$[146]$} \\
\hline Dectin-1 & Y238X & $\mathrm{R}$ & $\begin{array}{l}\text { Candida-colonized }(n=46) \text { versus noncolonized }(n=78) \text { HSCT patients } \\
(p<0.001)\end{array}$ & [65] \\
\hline Dectin-1 & Y238X & $D+R$ & IA $(n=39)$ versus no IA $(n=140)$ HSCT patients $(p=0.005)$ & [152] \\
\hline
\end{tabular}

D299G [138]. However, the extent to which these polymorphisms contribute to the hyperactivation immune status of CMC patients with autoimmune regulator gene mutations [139] is not known. IL-10 has been reported to inhibit the action of human monocytes against $C$. albicans [140], while in mice, the absence of IL-10 was associated with increased antifungal resistance [141]. However, in experimental candidiasis, IL-10 exhibited both beneficial and detrimental effects depending on the degree of inflammation (reviewed in [16]). Therefore, despite the overall suppressive effect, IL-10 might be required to limit host damage under high levels of inflammation, a mechanism that may ultimately determine whether or not successful control of the infection will ensue. This may explain why the D299G polymorphism does not appear to play a role in susceptibility and severity of human urogenital $C$. albicans infection [142]. TLR-2dependent IL-10 production was also demonstrated in response to Candida and Aspergillus in experimental models of infection [56,143]. However, in candidiasis, the nonsynonymous R753Q polymorphism in human TLR-2 was shown to reduce IFN- $\gamma$ and IL-8 and increase TNF- $\alpha$ during Candida sepsis in intensive care unit patients [144]. The extent to which this deregulated cytokine production contributes to susceptibility to candidiasis is still not clear. Furthermore, no association between R753Q and susceptibility to IA, chronic cavitary pulmonary aspergillosis (CCPA) or ABPA was found [145-147].

One of the first studies investigating the functional consequences of TLR-4 polymorphisms in aspergillosis described an increased frequency of CCPA among D299G carriers [146]. In CCPA patients, the fungus is able to grow in preformed lung cavities, therefore escaping immune surveillance. Considering that subjects harboring the D299G polymorphism have an additional defect in TLR- 4 function, the increased susceptibility observed is likely due to an extensive impairment in fungal recognition. In the stem cell transplantation setting, the D299G polymorphism in TLR-4 was also found to increase susceptibility to IA in HSCT recipients from unrelated donors [148]. The fact that a previous study failed to associate the same donor TLR- 4 polymorphism with IA in HSCT patients [147], further stresses that the contribution of the D299G polymorphism may depend on the type of transplant and associated clinical variables. In this regard, we have recently described an association between donor D299G and colonization by A. fumigatus, but not invasive disease, in a cohort of T-cell-depleted transplant recipients from related donors [145]. Therefore, fungal colonization may not predict susceptibility to infection in the presence of D299G, at least in this particular transplant setting. The contribution of this polymorphism to colonization by $A$. fumigatus could be explained by the fact that an abnormal TLR- 4 extracellular domain could be hampering its function by disrupting microbial recognition, eventually leading to fungal escape from immune surveillance. However, TLR-4 polymorphisms have also been shown to display a protective effect from hyperinflammatory diseases, including atherosclerosis and related conditions [149]. Therefore, the failure to recognize the fungus may be compensated by the lack of an exuberant inflammatory response to it which may ultimately be harmful to the host. In this regard, we have found that a hyperinflammatory state, more than the fungus itself, may contribute to susceptibility to aspergillosis and other fungal infections [22]. Thus, by limiting the inflammatory response to the fungus, the D299G polymorphism could contribute to resistance to aspergillosis, despite evidence of fungal growth. Interestingly, the D299G polymorphism was recently shown to have a unique distribution 


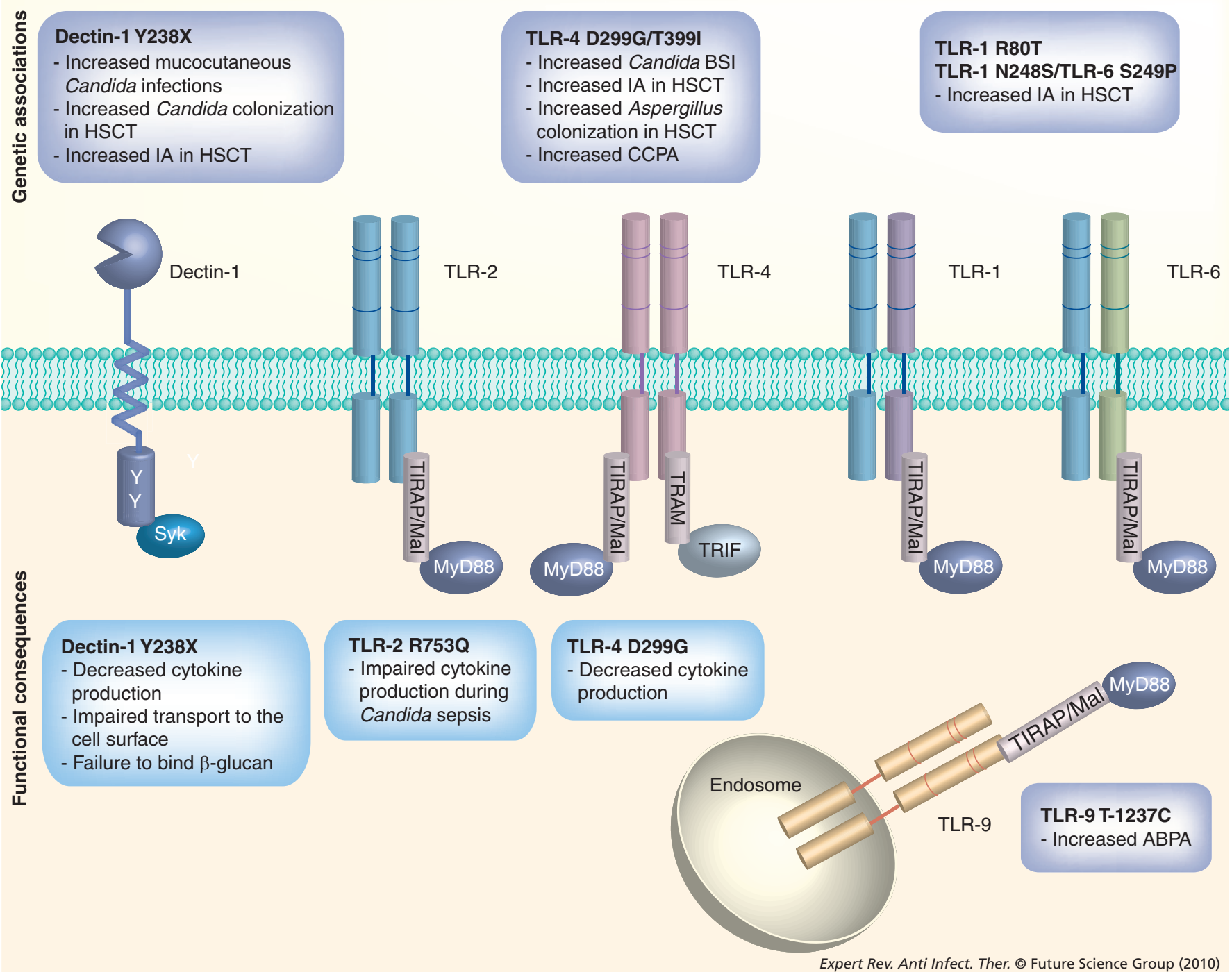

Figure 2. Human genetic polymorphisms in Toll-like receptors and Dectin-1 are associated with susceptibility to fungal infections and result in the functional impairment of the immune response to fungi.

ABPA: Allergic bronchopulmonary aspergillosis; BSI: Bloodstream infection; CCPA: Chronic cavitary pulmonary aspergillosis;

HSCT: Hematopoietic stem cell transplant; IA: Invasive aspergillosis; TLR: Toll-like receptor.

with high prevalence in Africa and low prevalence in Europe, with the authors arguing that the benefit from reduced inflammation during malaria in Africa might have been counter-selected due to lack of inflammation in response to bacterial infections [150]. Although TLR-4 has been representing the cornerstone of genetic variability to aspergillosis in the last few years, polymorphisms in other TLRs have also been linked with susceptibility to fungal infections. In particular, a common promoter polymorphism in TLR-9 (T-1237C) has been shown to predispose to ABPA, but not severe asthma with fungal sensitization [146] or IA following HSCT [145]. It is worth mentioning that we found this polymorphism to lead to an increase in TLR-9 gene expression in human mononuclear cells that could be further sustained upon TLR-9 engagement, presumably resulting in a gain-of-function of the receptor [Carvalho A, Almeida AJ, Osório NS et al., Manuscript Suвmitтed]. This observation is consistent with a role for TLR-9 in response to allergy since TLR-9-deficient mice have been shown to be more resistant to induced allergenic stimuli [115]. In addition, polymorphonuclear cells from these mice had an increased capacity to kill conidia and damage Aspergillus hyphae [70], therefore arguing for a detrimental role of this TLR-9 polymorphism and consequent enhancement of TLR-9 function in allergic aspergillosis. Moreover, less well-characterized genetic variants in other TLRs, including TLR-1 and -6, have also been reported to influence susceptibility to IA after HSCT [147]. Transplant recipients harboring either the R80T polymorphism in TLR-1 or a polymorphism combination in TLR-1 and -6 (N248S and S249P, respectively) have an increased risk of IA [147]. The fact that polymorphisms in HSCT recipients have been associated with aspergillosis suggests that other components in addition to hematopoietic cells play an important role in the recognition of Aspergillus ligands. 
Genetic variants affecting PRRs other than TLRs, in particular Dectin-1, have also been addressed as potential predictive factors for the incidence of fungal infections. A polymorphism in human Dectin-1 (Y238X) that generates an early stop codon was associated with recurrent mucocutaneous fungal infections in a Dutch family [65] and with Candida colonization after HSCT [39]. This polymorphism, leading to the loss of the last ten amino acids of the extracellular domain of Dectin-1, results in impaired transport to the cell surface as well as failure in mediating $\beta$-glucan binding [39]. Moreover, monocytes and macrophages of affected patients showed impaired cytokine responses (IL-6, TNF- $\alpha$ and IL-17), whereas neutrophils exhibited normal phagocytosis and killing of opsonized C. albicans, a finding likely contributing to the absence of invasive candidiasis in these patients. In addition, the role of the Dectin-1 pathway for antifungal host defense has been further supported by a study identifying a family with mutations in CARD9, displaying an almost complete defect in the generation of Th17 responses, rendering them more susceptible to mucocutaneous Candida infections [151].

We have also recently found that the functional Y238X polymorphism in Dectin-1 increased susceptibility to IA among HSCT patients [152]. The increased susceptibility to aspergillosis underlined by the Y238X polymorphism was found to rely on both donor and recipient genetic make-ups, with the effect being more prominent in conditions in which both donors and recipients simultaneously harbored the variant. Although Dectin-1 has been regarded as one major innate receptor leading to Th17 activation in response to Aspergillus [60], and the Y238X polymorphism was associated with impaired IL-17 production in response to $C$. albicans or $\beta$-glucan [153], we found that IFN- $\gamma$ and IL-10, in addition to IL-17A, production by human mononuclear cells harboring the $\mathrm{Y} 238 \mathrm{X}$ polymorphism were defective upon Aspergillus challenge [152]. Thus, these findings point to a previously unsuspected role for Dectin-1 in antifungal immunity, that is, the ability to modulate immunity and tolerance via IFN- $\gamma /$ IL-10 production, both cytokines reflecting the activation of protective Th1/Treg antifungal responses in mice [67] and humans [37]. The high risk of infection seen in conditions of recipient Dectin-1 deficiency also points to a crucial role for Dectin-1 expressed on nonhematopoietic cells in the induction of immune protection to the fungus. Incidentally, Dectin-1 has been shown to have an inducible expression in ECs and to play a critical role in mounting the innate immune responses in nonphagocytic cells [66]. Overall, these findings highlight the multiple roles Dectin-1 may have in host resistance to Aspergillus that is likely achieved through distinct, yet complementary, mechanisms of immune resistance and tolerance that are dependent on hematopoietic/nonhematopoietic compartmentalization.

\section{Expert commentary \& five-year view}

A finely orchestrated balance between activating and inhibitory signals is fundamental for the ability of the immune system to effectively attack and eliminate pathogenic fungi and/or coexist with commensals without reacting against self-antigens.
Derangements of this balance may underlie the pathogenesis of chronic infections and autoimmune inflammatory diseases. The new discoveries in the field of fungal immunology have offered new grounds for a better comprehension of cells and immune pathways that are amenable to manipulation in patients with or at risk of fungal infections. The very active research of the past few years has greatly improved our understanding of how the fungal pathogens are recognized as nonself by the host defense, allowing us to propose integrated models of innate recognition of these important human pathogens [54].

The use of TLR agonists has recently been explored and several clinical trials are currently underway in an attempt to target various TLRs for the development of vaccine adjuvants, antiinfectious agents and anticancer agents [154]. In this sense, a very important task of future studies will be to identify the adjuvant activity of specific PRR ligands in the context of fungal vaccination. Both combinations of various candidate vaccines with known and possibly novel TLR/CLR adjuvants are interesting options for the development of antifungal vaccines. Additional areas of investigation include a deepened understanding of TLR regulation, considering their role as 'double-edged swords' in promoting protective versus detrimental effects on antifungal immunity.

Finally, although the dissection of complex genetic traits modulating susceptibility to fungal infections is complex, the contribution of host genetics may hold the key to elucidate new risk factors for these severe, often fatal diseases. In this sense, new conceptual advances on the knowledge of host immunity also need to be accommodated from an immunogenetic point of view. Understanding host-pathogen interactions at the innate immune interface, together with the cellular and molecular bases affected by host genetic variables, will prove a very powerful research tool, allowing the identification of potential therapeutic targets and the design of prophylactic strategies exerting control over the outcome of immune pathways. The genetic screening of at-risk patients may ultimately be used to individualize treatments through the formulation of new targeted and patient-tailored antifungal therapeutics, likely improving the management and outcome of fungal infections.

\section{Acknowledgements}

The authors thank Cristina Massi Benedetti for digital art and editing.

\section{Financial \& competing interests disclosure}

This work was supported by the Specific Targeted Research Projects SYBARIS (FP7-HEALTH-2009), contract number 242220, and by the Italian Project PRIN 2007KLCKP8_004. Cristina Cunha and Agostinho Carvalho were financially supported by fellowships from Fundação para a Ciência e Tecnologia, Portugal (contracts SFRH/BD/65962/2009 and SFRH/BPD/46292/2008, respectively). The authors have no other relevant affiliations or financial involvement with any organization or entity with a financial interest in or financial conflict with the subject matter or materials discussed in the manuscript apart from those disclosed.

No writing assistance was utilized in the production of this manuscript. 


\section{Key issues}

- Although inflammation is an essential component of the protective response to fungi, its deregulation may significantly worsen fungal diseases and limit protective antifungal immune responses.

- Innate control of inflammation requires the specific recognition of invariant microbial molecular structures by pattern recognition receptors, of which Toll-like receptors and C-type lectin receptors are among the most important receptors.

- In addition to the role on protective immune activation, Toll-like receptor engagement may paradoxically promote the pathogenesis of fungal infections, by inducing inflammatory pathology and impairing antifungal immunity.

- Genetic variability of host innate immunity plays a determinant role in human susceptibility to fungal infections, specifically in high-risk patients such as those undergoing hematopoietic stem cell transplant.

- Novel therapeutic avenues and strategies for immunotherapy of fungal infections that attempt to limit inflammation, stimulating effective immune responses and that take into consideration the genetic variability of the host are required.

\section{References}

Papers of special note have been highlighted as:

- of interest

•• of considerable interest

1 Romani L. Overview of the fungal pathogens. In: Immunology of Infectious Diseases. Kaufman SHE, Sher A, Ahmed R (Eds). ASM Press, Washington DC, USA, 25-37 (2001).

2 Cooney NM, Klein BS. Fungal adaptation to the mammalian host: it is a new world, after all. Curr. Opin. Microbiol. 11(6), 511-516 (2008).

3 Hube B. Fungal adaptation to the host environment. Curr. Opin. Microbiol. 12(4), 347-349 (2009).

4 Antachopoulos C, Walsh TJ, Roilides E. Fungal infections in primary immunodeficiencies. Eur. J. Pediatr. 166(11), 1099-1117 (2007).

5 Carneiro-Sampaio M, Coutinho A. Immunity to microbes: lessons from primary immunodeficiencies. Infect. Immun. 75(4), 1545-1555 (2007).

- Overview of host-fungus relationships based on clinical features of primary immunodeficiency patients.

6 Pappas PG, Alexander BD, Andes DR et al. Invasive fungal infections among organ transplant recipients: results of the Transplant-Associated Infection Surveillance Network (TRANSNET). Clin. Infect. Dis. 50(8), 1101-1111 (2010).

7 Kontoyiannis DP, Marr KA, Park BJ et al. Prospective surveillance for invasive fungal infections in hematopoietic stem cell transplant recipients, 2001-2006: overview of the Transplant-Associated Infection Surveillance Network (TRANSNET) Database. Clin. Infect. Dis. 50(8), 1091-1100 (2010).

8 Singh N, Perfect JR. Immune reconstitution syndrome associated with opportunistic mycoses. Lancet Infect. Dis. 7(6), 395-401 (2007).
- Review on the conceptual principles of immune reconstitution syndrome as a predisposing factor to fungal infections.

9 Simon-Nobbe B, Denk U, Poll V, Rid R, Breitenbach M. The spectrum of fungal allergy. Int. Arch. Allergy Immunol. 145(1), 58-86 (2008).

10 Denning DW, O’Driscoll BR, Hogaboam CM, Bowyer P, Niven RM. The link between fungi and severe asthma: a summary of the evidence. Eur. Respir. J. 27(3), 615-626 (2006).

11 Romani L, Puccetti P. Immune regulation and tolerance to fungi in the lungs and skin. Chem. Immunol. Allergy 94, 124-137 (2008).

12 Odds FC, Jacobsen MD. Multilocus sequence typing of pathogenic Candida species. Eukaryot. Cell 7(7), 1075-1084 (2008).

13 Romani L. Immunity to fungal infections. Nat. Rev. Immunol. 4(1), 1-23 (2004).

14 Shoham S, Levitz SM. The immune response to fungal infections. Br. J. Haematol. 129(5), 569-582 (2005).

15 Romani L, Fallarino F, De Luca A et al. Defective tryptophan catabolism underlies inflammation in mouse chronic granulomatous disease. Nature 451(7175), 211-215 (2008).

- Case of susceptibility to a fungal infection as a genetically determined failure to control inflammation.

16 Romani L, Puccetti P. Protective tolerance to fungi: the role of IL-10 and tryptophan catabolism. Trends Microbiol. 14(4), 183-189 (2006).

17 Filipe-Santos O, Bustamante J, Chapgier A et al. Inborn errors of IL-12/23- and IFN- $\gamma$-mediated immunity: molecular, cellular, and clinical features. Semin. Immunol. 18(6), 347-361 (2006).

18 Lilic D. New perspectives on the immunology of chronic mucocutaneous candidiasis. Curr. Opin. Infect. Dis. 15(2), 143-147 (2002).
19 Zhou L, Chong MM, Littman DR. Plasticity of CD4 ${ }^{+} \mathrm{T}$ cell lineage differentiation. Immunity 30(5), 646-655 (2009).

20 Korn T, Bettelli E, Oukka M, Kuchroo VK. IL-17 and Th17 Cells. Annu. Rev. Immunol. 27, 485-517 (2009).

21 Dong C. Diversification of T-helper-cell lineages: finding the family root of IL-17-producing cells. Nat. Rev. Immunol. 6(4), 329-333 (2006).

22 Romani L, Puccetti P. Controlling pathogenic inflammation to fungi. Expert Rev. Anti Infect. Ther. 5(6), 1007-1017 (2007).

23 Carvalho A, Cunha C, Di Ianni M et al. Prognostic significance of genetic variants in the IL-23/Th17 pathway for the outcome of T cell-depleted allogeneic stem cell transplantation. Bone Marrow Transplant. DOI: 10.1038/bmt.2010.28 (2010) (Epub ahead of print).

24 Happel KI, Dubin PJ, Zheng M et al. Divergent roles of IL-23 and IL-12 in host defense against Klebsiella pneumoniae. J. Exp. Med. 202(6), 761-769 (2005).

25 Zelante T, De Luca A, Bonifazi P et al. IL-23 and the Th17 pathway promote inflammation and impair antifungal immune resistance. Eur. J. Immunol. 37(10), 2695-2706 (2007).

26 De Luca A, Montagnoli C, Zelante T et al. Functional yet balanced reactivity to Candida albicans requires TRIF, MyD88, and IDO-dependent inhibition of Rorc. J. Immunol. 179(9), 5999-6008 (2007).

27 Heninger E, Hogan LH, Karman J et al. Characterization of the Histoplasma capsulatum-induced granuloma. J. Immunol. 177(5), 3303-3313 (2006).

28 Leibundgut-Landmann S, Gross O, Robinson MJ et al. Syk- and CARD9dependent coupling of innate immunity to the induction of $\mathrm{T}$ helper cells that produce interleukin 17. Nat. Immunol. 8(6), 630-638 (2007). 
29 van de Veerdonk FL, Marijnissen RJ, Kullberg BJ et al. The macrophage mannose receptor induces IL-17 in response to Candida albicans. Cell Host Microbe 5(4), 329-340 (2009).

30 Kleinschek MA, Muller U, Brodie SJ et al. IL-23 enhances the inflammatory cell response in Cryptococcus neoformans infection and induces a cytokine pattern distinct from IL-12. J. Immunol. 176(2), 1098-1106 (2006)

31 Rizzetto L, Kuka M, De Filippo C et al. Differential IL-17 production and mannan recognition contribute to fungal pathogenicity and commensalism. J. Immunol. 184(8), 4258-4268 (2010).

32 Armstrong-James DP, Turnbull SA, Teo I et al. Impaired interferon- $\gamma$ responses, increased interleukin-17 expression, and a tumor necrosis factor- $\alpha$ transcriptional program in invasive aspergillosis. J. Infect. Dis. 200(8), 1341-1351 (2009).

33 Zhang Y, Wang F, Tompkins KC et al. Robust Th1 and Th17 immunity supports pulmonary clearance but cannot prevent systemic dissemination of highly virulent Cryptococcus neoformans H99. Am. J. Pathol. 175(6), 2489-2500 (2009).

34 Fenoglio D, Poggi A, Catellani S et al. Vdelta1 T lymphocytes producing IFN- $\gamma$ and IL-17 are expanded in HIV-1-infected patients and respond to Candida albicans. Blood 113(26), 6611-6618 (2009).

35 Acosta-Rodriguez EV, Napolitani G, Lanzavecchia A, Sallusto F. Interleukins $1 \beta$ and 6 but not transforming growth factor- $\beta$ are essential for the differentiation of interleukin 17-producing human T helper cells. Nat. Immunol. 8(9), 942-949 (2007).

36 Bozza S, Clavaud C, Giovannini G et al. Immune sensing of Aspergillus fumigatus proteins, glycolipids, and polysaccharides and the impact on Th immunity and vaccination. J. Immunol. 183, 2407-2414 (2009).

37 Chai LY, van de Veerdonk F, Marijnissen $\mathrm{RJ}$ et al. Anti-Aspergillus human host defence relies on type $1 \mathrm{~T}$ helper (Th1), rather than type $17 \mathrm{~T}$ helper (Th17), cellular immunity. Immunology 130(1), 46-54 (2009).

38 Milner JD, Brenchley JM, Laurence A et al. Impaired $\mathrm{T}(\mathrm{H}) 17$ cell differentiation in subjects with autosomal dominant hyper-IgE syndrome. Nature 452(7188), 773-776 (2008).

- Description of defective Th17 cell activation in susceptibility to fungal infections in hyper-IgE syndrome.
39 Ferwerda B, Ferwerda G, Plantinga TS et al. Human Dectin-1 deficiency and mucocutaneous fungal infections. N. Engl. J. Med. 361(18), 1760-1767 (2009).

-• Identification of a Dectin-1 polymorphism predisposing to mucocutaneous fungal infections.

40 Conti HR, Shen F, Nayyar N et al. Th17 cells and IL-17 receptor signaling are essential for mucosal host defense against oral candidiasis. J. Exp. Med. 206(2), 299-311 (2009).

41 Huang W, Na L, Fidel PL, Schwarzenberger P. Requirement of interleukin-17A for systemic anti-Candida albicans host defense in mice. J. Infect. Dis. 190(3), 624-631 (2004).

42 Zelante T, De Luca A, D’Angelo C, Moretti S, Romani L. IL-17/Th17 in anti-fungal immunity: what's new? Eur. J. Immunol. 39(3), 645-648 (2009).

43 De Luca A, Zelante T, D’Angelo C et al. IL-22 defines a novel immune pathway of antifungal resistance. Mucosal Immunol. 3(4), 361-373 (2010).

44 Romani L, Zelante T, De Luca A, Fallarino F, Puccetti P. IL-17 and therapeutic kynurenines in pathogenic inflammation to fungi. J. Immunol. 180(8), 5157-5162 (2008).

45 Zenewicz LA, Flavell RA. IL-22 and inflammation: leukin' through a glass onion. Eur. J. Immunol. 38(12), 3265-3268 (2008).

46 Akira S, Uematsu S, Takeuchi O. Pathogen recognition and innate immunity. Cell 124(4), 783-801 (2006).

47 Gribar SC, Richardson WM, Sodhi CP, Hackam DJ. No longer an innocent bystander: epithelial Toll-like receptor signaling in the development of mucosal inflammation. Mol. Med. 14(9-10), 645-659 (2008).

48 Weindl G, Naglik JR, Kaesler S et al. Human epithelial cells establish direct antifungal defense through TLR4mediated signaling. J. Clin. Invest. 117(12), 3664-3672 (2007).

-• Characterization of the involvement of human epithelial Toll-like receptor (TLR)-4 in mucosal antifungal immunity.

49 De Luca A, Bozza S, Zelante T et al. Nonhematopoietic cells contribute to protective tolerance to Aspergillus fumigatus via a TRIF pathway converging on IDO. Cell. Mol. Immunol. DOI:10.1038/cmi.2010.43 (2010) (Epub ahead of print).
50 Mayer AK, Bartz H, Fey F, Schmidt LM, Dalpke AH. Airway epithelial cells modify immune responses by inducing an anti-inflammatory microenvironment. Eur. J. Immunol. 38(6), 1689-1699 (2008).

51 Balloy V, Sallenave JM, Wu Y et al. Aspergillus fumigatus-induced interleukin-8 synthesis by respiratory epithelial cells is controlled by the phosphatidylinositol 3-kinase, p38 MAPK, and ERK1/2 pathways and not by the Toll-like receptor-MyD88 pathway. J. Biol. Chem. 283(45), 30513-30521 (2008).

52 Reaves TA, Chin AC, Parkos CA Neutrophil transepithelial migration: role of Toll-like receptors in mucosal inflammation. Mem. Inst. Oswaldo Cruz 100(Suppl. 1), 191-198 (2005).

53 Chignard M, Balloy V, Sallenave JM, Si-Tahar M. Role of Toll-like receptors in lung innate defense against invasive aspergillosis. Distinct impact in immunocompetent and immunocompromized hosts. Clin. Immunol. 124(3), 238-243 (2007).

54 Netea MG, Brown GD, Kullberg BJ, Gow NA. An integrated model of the recognition of Candida albicans by the innate immune system. Nat. Rev. Microbiol. 6(1), 67-78 (2008).

55 Romani L. Cell mediated immunity to fungi: a reassessment. Med. Mycol. 46(6), 515-529 (2008).

56 Bellocchio S, Montagnoli C, Bozza S et al. The contribution of the Toll-like/IL-1 receptor superfamily to innate and adaptive immunity to fungal pathogens in vivo. J. Immunol. 172(5), 3059-3069 (2004).

57 Brown GD. Dectin-1: a signalling non-TLR pattern-recognition receptor. Nat. Rev. Immunol. 6(1), 33-43 (2006).

58 Gantner BN, Simmons RM, Underhill DM. Dectin-1 mediates macrophage recognition of Candida albicans yeast but not filaments. EMBO J. 24(6), 1277-1286 (2005).

59 Saijo S, Fujikado N, Furuta T et al. Dectin-1 is required for host defense against Pneumocystis carinii but not against Candida albicans. Nat. Immunol. 8(1), 39-46 (2007).

60 Werner JL, Metz AE, Horn D et al. Requisite role for the Dectin-1 $\beta$-glucan receptor in pulmonary defense against Aspergillus fumigatus. J. Immunol. 182(8), 4938-4946 (2009). 
61 Gross O, Gewies A, Finger K et al. Card9 controls a non-TLR signalling pathway for innate anti-fungal immunity. Nature 442(7103), 651-656 (2006).

-• Description of a non-TLR signaling pathway controlling innate antifungal immunity.

62 Gringhuis SI, den Dunnen J, Litjens M et al. Dectin-1 directs T helper cell differentiation by controlling noncanonical NF- $\kappa \mathrm{B}$ activation through Raf- 1 and Syk. Nat. Immunol. 10 (2), 203-213 (2009).

63 Heinsbroek SE, Brown GD, Gordon S. Dectin-1 escape by fungal dimorphism. Trends Immunol. 26(7), 352-354 (2005).

64 Rappleye CA, Eissenberg LG, Goldman WE. Histoplasma capsulatum $\alpha-(1,3)-$ glucan blocks innate immune recognition by the $\beta$-glucan receptor. Proc. Natl Acad. Sci. USA 104(4), 1366-1370 (2007).

65 Plantinga TS, van der Velden WJ, Ferwerda B et al. Early stop polymorphism in human DECTIN-1 is associated with increased Candida colonization in hematopoietic stem cell transplant recipients. Clin. Infect. Dis. 49(5), 724-732 (2009).

66 Lee HM, Yuk JM, Shin DM, Jo EK. Dectin-1 is inducible and plays an essential role for mycobacteria-induced innate immune responses in airway epithelial cells. J. Clin. Immunol. 29(6), 795-805 (2009).

67 Bonifazi P, D’Angelo C, Zagarella S et al. Intranasally delivered siRNA targeting $\mathrm{PI} 3 \mathrm{~K} / \mathrm{Akt} / \mathrm{mTOR}$ inflammatory pathways protects from aspergillosis. Mucosal Immunol. 3(2), 193-205 (2010).

68 Bonifazi P, Zelante T, D’Angelo C et al. Balancing inflammation and tolerance in vivo through dendritic cells by the commensal Candida albicans. Mucosal Immunol. 2(4), 362-374 (2009).

69 Puccetti P, Grohmann U. IDO and regulatory $\mathrm{T}$ cells: a role for reverse signalling and non-canonical NF- $\kappa \mathrm{B}$ activation. Nat. Rev. Immunol. 7(10), 817-823 (2007).

70 Bellocchio S, Moretti S, Perruccio K et al. TLRs govern neutrophil activity in aspergillosis. J. Immunol. 173(12), 7406-7415 (2004).

71 van de Veerdonk FL, Kullberg BJ, van der Meer JW, Gow NA, Netea MG.

Host-microbe interactions: innate pattern recognition of fungal pathogens. Curr. Opin. Microbiol. 11(4), 305-312 (2008).

72 Behnsen J, Narang P, Hasenberg M et al. Environmental dimensionality controls the interaction of phagocytes with the pathogenic fungi Aspergillus fumigatus and Candida albicans. PLoS Pathog. 3(2), e13 (2007).

73 Said-Sadier N, Padilla E, Langsley G, Ojcius DM. Aspergillus fumigatus stimulates the NLRP3 inflammasome through a pathway requiring ROS production and the Syk tyrosine kinase. PLoS One 5(4), e10008 (2010).

74 Kumar H, Kumagai Y, Tsuchida T et al. Involvement of the NLRP3 inflammasome in innate and humoral adaptive immune responses to fungal $\beta$-glucan. J. Immunol. 183(12), 8061-8067 (2009).

75 Gross O, Poeck H, Bscheider M et al. Syk kinase signalling couples to the Nlrp3 inflammasome for anti-fungal host defence. Nature 459(7245), 433-436 (2009).

- Description of Syk coupling with NLRP3 inflammasome activation in antifungal host defense.

76 Hise AG, Tomalka J, Ganesan S et al. An essential role for the NLRP3 inflammasome in host defense against the human fungal pathogen Candida albicans. Cell Host Microbe 5(5), 487-497 (2009).

77 Joly S, Ma N, Sadler JJ et al. Cutting edge: Candida albicans hyphae formation triggers activation of the Nlrp3 inflammasome. J. Immunol. 183(6), 3578-3581 (2009).

78 Lev-Sagie A, Prus D, Linhares IM et al. Polymorphism in a gene coding for the inflammasome component NALP3 and recurrent vulvovaginal candidiasis in women with vulvar vestibulitis syndrome. Am. J. Obstet. Gynecol. 200 (3), 303 e301-e306 (2009).

79 Bauernfeind FG, Horvath G, Stutz A et al. Cutting edge: NF- $\kappa \mathrm{B}$ activating pattern recognition and cytokine receptors license NLRP3 inflammasome activation by regulating NLRP3 expression. J. Immunol. 183(2), 787-791 (2009).

80 Trinchieri G, Sher A. Cooperation of Toll-like receptor signals in innate immune defence. Nat. Rev. Immunol. 7(3), 179-190 (2007).

81 Chai LY, Kullberg BJ, Vonk AG et al. Modulation of Toll-like receptor 2 (TLR2) and TLR4 responses by Aspergillus fumigatus. Infect. Immun. 77(5), 2184-2192 (2009).

82 Lemaitre B, Nicolas E, Michaut L, Reichhart JM, Hoffmann JA. The dorsoventral regulatory gene cassette spatzle/ Toll/cactus controls the potent antifungal response in Drosophila adults. Cell 86(6), 973-983 (1996).

83 Carvalho A, Cunha C, Pasqualotto AC et al. Genetic variability of innate immunity impacts human susceptibility to fungal diseases. Int. J. Infect. Dis. 14(6), e460-e468 (2009).

84 Jouault T, Ibata-Ombetta S, Takeuchi O et al. Candida albicans phospholipomannan is sensed through Toll-like receptors. J. Infect. Dis. 188(1), 165-172 (2003).

85 Netea MG, Van Der Graaf CA, Vonk AG et al. The role of to-ll-like receptor (TLR) 2 and TLR 4 in the host defense against disseminated candidiasis. J. Infect. Dis. 185(10), 1483-1489 (2002).

86 Villamon E, Gozalbo D, Roig P et al. Toll-like receptor-2 is essential in murine defenses against Candida albicans infections. Microbes Infect. 6(1), 1-7 (2004).

87 Blasi E, Mucci A, Neglia R et al. Biological importance of the two Toll-like receptors, TLR 2 and TLR4, in macrophage response to infection with Candida albicans. FEMS Immunol. Med. Microbiol. 44(1), 69-79 (2005).

88 Yanez A, Flores A, Murciano C et al. Signalling through TLR2/MyD88 induces differentiation of murine bone marrow stem and progenitor cells to functional phagocytes in response to Candida albicans. Cell. Microbiol. 12(1), 114-128 (2010).

89 Netea MG, van de Veerdonk F, Verschueren I, van der Meer JW, Kullberg BJ. Role of TLR1 and TLR6 in the host defense against disseminated candidiasis. FEMS Immunol. Med. Microbiol. 52(1), 118-123 (2008).

90 Wang JE, Warris A, Ellingsen EA et al. Involvement of CD14 and Toll-like receptors in activation of human monocytes by Aspergillus fumigatus hyphae. Infect. Immun. 69(4), 2402-2406 (2001).

91 Balloy V, Si-Tahar M, Takeuchi O et al. Involvement of Toll-like receptor 2 in experimental invasive pulmonary aspergillosis. Infect. Immun. 73(9), 5420-5425 (2005).

92 Shoham S, Huang C, Chen JM, Golenbock DT, Levitz SM. Toll-like receptor 4 mediates intracellular signaling without TNF- $\alpha$ release in response to Cryptococcus neoformans polysaccharide capsule. J. Immunol. 166(7), 4620-4626 (2001).

93 Biondo C, Midiri A, Messina L et al. MyD88 and TLR2, but not TLR4, are required for host defense against Cryptococcus neoformans. Eur. J. Immunol. 35(3), 870-878 (2005).

94 Yauch LE, Mansour MK, Shoham S, Rottman JB, Levitz SM. Involvement of CD14, Toll-like receptors 2 and 4, and 
MyD88 in the host response to the fungal pathogen Cryptococcus neoformans in vivo. Infect. Immun. 72(9), 5373-5382 (2004).

VL. TLR2 is a negative regulator of Th17 cells and tissue pathology in a pulmonary model of fungal infection. J. Immunol. 183(2), 1279-1290 (2009).

96 Tada H, Nemoto E, Shimauchi $\mathrm{H}$ et al. Saccharomyces cerevisiae- and Candida albicans-derived mannan induced production of tumor necrosis factor $\alpha$ by human monocytes in a CD14- and Toll-like receptor 4-dependent manner. Microbiol. Immunol. 46(7), 503-512 (2002).

97 Netea MG, Gow NA, Munro CA et al. Immune sensing of Candida albicans requires cooperative recognition of mannans and glucans by lectin and Toll-like receptors. J. Clin. Invest. 116(6), 1642-1650 (2006).

98 Gasparoto TH, Tessarolli V, Garlet TP et al. Absence of functional TLR4 impairs response of macrophages after Candida albicans infection. Med. Mycol. DOI: 10.3109/13693786.2010.481292 (2010) (Epub ahead of print).

99 d'Ostiani CF, Del Sero G, Bacci A et al. Dendritic cells discriminate between yeasts and hyphae of the fungus Candida albicans. Implications for initiation of $T$ helper cell immunity in vitro and in vivo. J. Exp. Med. 191(10), 1661-1674 (2000).

100 Villamon E, Gozalbo D, Roig P et al. Myeloid differentiation factor 88 (MyD88) is required for murine resistance to Candida albicans and is critically involved in Candida-induced production of cytokines. Eur. Cytokine Netw. 15(3), 263-271 (2004).

101 Marr KA, Balajee SA, Hawn TR et al. Differential role of MyD88 in macrophagemediated responses to opportunistic fungal pathogens. Infect. Immun. 71(9), 5280-5286 (2003).

102 Romani L, Bistoni F, Perruccio K et al. Thymosin $\alpha 1$ activates dendritic cell tryptophan catabolism and establishes a regulatory environment for balance of inflammation and tolerance. Blood 108(7), 2265-2274 (2006)

103 Mambula SS, Sau K, Henneke P, Golenbock DT, Levitz SM. Toll-like receptor (TLR) signaling in response to Aspergillus fumigatus. J. Biol. Chem. 277(42), 39320-39326 (2002).

104 Bozza S, Zelante T, Moretti S et al. Lack of Toll IL-1R8 exacerbates Th17 cell responses in fungal infection. J. Immunol. 180(6), 4022-4031 (2008).
105 Dubourdeau M, Athman R, Balloy V et al. Aspergillus fumigatus induces innate immune responses in alveolar macrophages through the MAPK pathway independently of TLR2 and TLR4. J. Immunol. 177(6), 3994-4001 (2006).

106 Bretz C, Gersuk G, Knoblaugh S et al. MyD88 signaling contributes to early pulmonary responses to Aspergillus fumigatus. Infect. Immun. 76(3), 952-958 (2008).

107 Rivera A, Ro G, Van Epps HL et al. Innate immune activation and $\mathrm{CD}^{+} \mathrm{T}$ cell priming during respiratory fungal infection. Immunity 25(4), 665-675 (2006).

108 Ding K, Shibui A, Wang Y et al. Impaired recognition by Toll-like receptor 4 is responsible for exacerbated murine Pneumocystis pneumonia. Microbes Infect. 7(2), 195-203 (2005).

109 Nakamura K, Miyagi K, Koguchi Y et al. Limited contribution of Toll-like receptor 2 and 4 to the host response to a fungal infectious pathogen, Cryptococcus neoformans. FEMS Immunol. Med. Microbiol. 47(1), 148-154 (2006).

110 Loures FV, Pina A, Felonato M et al. Toll-like receptor 4 signaling leads to severe fungal infection associated with enhanced proinflammatory immunity and impaired expansion of regulatory T cells. Infect. Immun. 78(3), 1078-1088 (2010).

111 Miyazato A, Nakamura K, Yamamoto N et al. Toll-like receptor 9-dependent activation of myeloid dendritic cells by deoxynucleic acids from Candida albicans. Infect. Immun. 77(7), 3056-3064 (2009).

112 Nakamura K, Miyazato A, Xiao G et al. Deoxynucleic acids from Cryptococcus neoformans activate myeloid dendritic cells via a TLR9-dependent pathway. J. Immunol. 180(6), 4067-4074 (2008).

113 Ramirez-Ortiz ZG, Specht CA, Wang JP et al. Toll-like receptor 9-dependent immune activation by unmethylated $\mathrm{CpG}$ motifs in Aspergillus fumigatus DNA. Infect. Immun. 76(5), 2123-2129 (2008).

114 Bozza S, Gaziano R, Lipford GB et al. Vaccination of mice against invasive aspergillosis with recombinant Aspergillus proteins and $\mathrm{CpG}$ oligodeoxynucleotides as adjuvants. Microbes Infect. 4(13), 1281-1290 (2002).

115 Ramaprakash H, Ito T, Standiford TJ, Kunkel SL, Hogaboam CM. Toll-like receptor 9 modulates immune responses to Aspergillus fumigatus conidia in immunodeficient and allergic mice. Infect. Immun. 77(1), 108-119 (2009).
116 Park SJ, Hughes MA, Burdick M, Strieter RM, Mehrad B. Early NK cell-derived IFN- $\gamma$ is essential to host defense in neutropenic invasive aspergillosis. J. Immunol. 182(7), 4306-4312 (2009).

117 Steele C, Rapaka RR, Metz A et al. The $\beta$-glucan receptor Dectin-1 recognizes specific morphologies of Aspergillus fumigatus. PLoS Pathog. 1(4), e42 (2005).

118 Taylor PR, Tsoni SV, Willment JA et al. Dectin-1 is required for $\beta$-glucan recognition and control of fungal infection. Nat. Immunol. 8(1), 31-38 (2007).

119 Nakamura K, Kinjo T, Saijo S et al. Dectin-1 is not required for the host defense to Cryptococcus neoformans. Microbiol. Immunol. 51(11), 1115-1119 (2007).

120 Giles SS, Dagenais TR, Botts MR, Keller NP, Hull CM. Elucidating the pathogenesis of spores from the human fungal pathogen Cryptococcus neoformans. Infect. Immun. 77(8), 3491-3500 (2009).

121 Bonfim CV, Mamoni RL, Blotta MH. TLR-2, TLR-4 and Dectin-1 expression in human monocytes and neutrophils stimulated by Paracoccidioides brasiliensis. Med. Mycol. 47(7), 722-733 (2009).

122 Gow NA, Netea MG, Munro CA et al. Immune recognition of Candida albicans $\beta$-glucan by Dectin-1. J. Infect. Dis. 196(10), 1565-1571 (2007).

123 Brown GD, Herre J, Williams DL et al. Dectin-1 mediates the biological effects of $\beta$-glucans. J. Exp. Med. 197(9), 1119-1124 (2003).

124 Gantner BN, Simmons RM, Canavera SJ, Akira S, Underhill DM. Collaborative induction of inflammatory responses by Dectin-1 and Toll-like receptor 2. J. Exp. Med. 197(9), 1107-1117 (2003).

125 Dennehy KM, Ferwerda G, Faro-Trindade I et al. Syk kinase is required for collaborative cytokine production induced through Dectin-1 and Toll-like receptors. Eur. J. Immunol. 38(2), 500-506 (2008).

126 Dillon S, Agrawal S, Banerjee K et al. Yeast zymosan, a stimulus for TLR2 and Dectin-1, induces regulatory antigenpresenting cells and immunological tolerance. J. Clin. Invest. 116(4), 916-928 (2006).

127 Luther K, Torosantucci A, Brakhage AA, Heesemann J, Ebel F. Phagocytosis of Aspergillus fumigatus conidia by murine macrophages involves recognition by the Dectin-1 $\beta$-glucan receptor and Toll-like receptor 2. Cell Microbiol. 9(2), 368-381 (2007). 
128 Toyotome T, Adachi Y, Watanabe A et al. Activator protein 1 is triggered by Aspergillus fumigatus $\beta$-glucans surfaceexposed during specific growth stages. Microb. Pathog. 44(2), 141-150 (2008).

129 Jouault T, El Abed-El Behi M, MartinezEsparza $\mathrm{M}$ et al. Specific recognition of Candida albicans by macrophages requires galectin-3 to discriminate Saccharomyces cerevisiae and needs association with TLR2 for signaling. J. Immunol. 177(7), 4679-4687 (2006).

130 Agrawal S, Agrawal A, Doughty B et al. Cutting edge: different Toll-like receptor agonists instruct dendritic cells to induce distinct $T h$ responses via differential modulation of extracellular signalregulated kinase-mitogen-activated protein kinase and c-Fos. J. Immunol. 171(10), 4984-4989 (2003).

131 Gringhuis SI, den Dunnen J, Litjens M et al. C-type lectin DC-SIGN modulates Toll-like receptor signaling via Raf-1 kinase-dependent acetylation of transcription factor NF- $\kappa \mathrm{B}$. Immunity 26(5), 605-616 (2007).

132 Garantziotis S, Hollingsworth JW, Zaas AK, Schwartz DA. The effect of Toll-like receptors and Toll-like receptor genetics in human disease. Annu. Rev. Med. 59, 343-359 (2008).

133 Lasker MV, Nair SK. Intracellular TLR signaling: a structural perspective on human disease. J. Immunol. 177(1), 11-16 (2006).

134 Rallabhandi P, Bell J, Boukhvalova MS et al. Analysis of TLR4 polymorphic variants: new insights into TLR4/MD-2/CD14 stoichiometry, structure, and signaling. J. Immunol. 177(1), 322-332 (2006).

135 Arbour NC, Lorenz E, Schutte BC et al. TLR4 mutations are associated with endotoxin hyporesponsiveness in humans. Nat. Genet. 25(2), 187-191 (2000).

136 Michel O, LeVan TD, Stern D et al. Systemic responsiveness to lipopolysaccharide and polymorphisms in the Toll-like receptor 4 gene in human beings. J. Allergy Clin. Immunol. 112(5), 923-929 (2003).

137 Van der Graaf CA, Netea MG, Morre SA et al. Toll-like receptor 4 Asp299Gly/ Thr399Ile polymorphisms are a risk factor for Candida bloodstream infection. Eur. Cytokine Netw. 17(1), 29-34 (2006).

138 van der Graaf CA, Netea MG, Drenth IP et al. Candida-specific interferon- $\gamma$ deficiency and Toll-like receptor polymorphisms in patients with chronic mucocutaneous candidiasis. Neth. J. Med. 61(11), 365-369 (2003).
139 Ryan KR, Hong M, Arkwright PD et al. Impaired dendritic cell maturation and cytokine production in patients with chronic mucocutanous candidiasis with or without APECED. Clin. Exp. Immunol. 154(3), 406-414 (2008).

140 Roilides E, Anastasiou-Katsiardani A, Dimitriadou-Georgiadou A et al. Suppressive effects of interleukin-10 on human mononuclear phagocyte function against Candida albicans and Staphylococcus aureus. J. Infect. Dis. 178(6), 1734-1742 (1998).

141 Del Sero G, Mencacci A, Cenci E et al. Antifungal type 1 responses are upregulated in IL-10-deficient mice. Microbes Infect. 1(14), 1169-1180 (1999).

142 Morre SA, Murillo LS, Spaargaren J, Fennema HS, Pena AS. Role of the Toll-like receptor 4 Asp299Gly polymorphism in susceptibility to Candida albicans infection. J. Infect. Dis. 186(9), 1377-1379; author reply 1379 (2002).

143 Netea MG, Sutmuller R, Hermann C et al. Toll-like receptor 2 suppresses immunity against Candida albicans through induction of IL-10 and regulatory T cells. J. Immunol. 172(6), 3712-3718 (2004).

144 Woehrle T, Du W, Goetz A et al. Pathogen specific cytokine release reveals an effect of TLR2 Arg753Gln during Candida sepsis in humans. Cytokine 41(3), 322-329 (2008).

145 Carvalho A, Cunha C, Carotti A et al. Polymorphisms in Toll-like receptor genes and susceptibility to infections in allogeneic stem cell transplantation. Exp. Hematol. 37(9), 1022-1029 (2009).

146 Carvalho A, Pasqualotto AC, Pitzurra L et al. Polymorphisms in Toll-like receptor genes and susceptibility to pulmonary aspergillosis. J. Infect. Dis. 197(4), 618-621 (2008).

147 Kesh S, Mensah NY, Peterlongo P et al. TLR1 and TLR6 polymorphisms are associated with susceptibility to invasive aspergillosis after allogeneic stem cell transplantation. Ann. NY Acad. Sci. 1062, 95-103 (2005).

148 Bochud PY, Chien JW, Marr KA et al. Toll-like receptor 4 polymorphisms and aspergillosis in stem-cell transplantation. N. Engl. J. Med. 359 (17), 1766-1777 (2008).

- Description of TLR-4 polymorphisms as strong predictive factors for invasive aspergillosis in stem cell transplanted patients.
149 Kiechl S, Lorenz E, Reindl M et al. Toll-like receptor 4 polymorphisms and atherogenesis. N. Engl. J. Med. 347(3), 185-192 (2002).

150 Ferwerda B, McCall MB, Alonso S et al. TLR4 polymorphisms, infectious diseases, and evolutionary pressure during migration of modern humans. Proc. Natl Acad. Sci. USA 104(42), 16645-16650 (2007).

151 Glocker EO, Hennigs A, Nabavi M et al. A homozygous CARD9 mutation in a family with susceptibility to fungal infections. N. Engl. J. Med. 361(18), 1727-1735 (2009).

152 Cunha C, Di Ianni M, Bozza S et al. Dectin-1 Y238X polymorphism associates with susceptibility to invasive aspergillosis in hematopoietic transplantation through impairment of both recipient- and donor-dependent mechanisms of antifungal immunity. Blood DOI 10.1182/ blood-2010-04-279307 (2010) (Epub ahead of print).

153 de Vries HS, Plantinga TS, van Krieken $\mathrm{JH}$ et al. Genetic association analysis of the functional c. $714 \mathrm{~T}>\mathrm{G}$ polymorphism and mucosal expression of Dectin-1 in inflammatory bowel disease. PLoS One 4(11), e7818 (2009).

154 Romagne F. Current and future drugs targeting one class of innate immunity receptors: the Toll-like receptors. Drug Discov. Today 12(1-2), 80-87 (2007).

155 McKinley L, Logar AJ, McAllister F et al. Regulatory $\mathrm{T}$ cells dampen pulmonary inflammation and lung injury in an animal model of pneumocystis pneumonia. J. Immunol. 177(9), 6215-6226 (2006).

156 Montagnoli C, Bacci A, Bozza S et al. B7/CD28-dependent CD $4{ }^{+} \mathrm{CD} 25^{+}$ regulatory $\mathrm{T}$ cells are essential components of the memory-protective immunity to Candida albicans. J. Immunol. 169(11), 6298-6308 (2002).

157 Montagnoli C, Fallarino F, Gaziano R et al. Immunity and tolerance to Aspergillus involve functionally distinct regulatory $\mathrm{T}$ cells and tryptophan catabolism. J. Immunol. 176(3), 1712-1723 (2006).

158 Cavassani KA, Campanelli AP, Moreira AP et al. Systemic and local characterization of regulatory $\mathrm{T}$ cells in a chronic fungal infection in humans. J. Immunol. 177(9), 5811-5818 (2006).

159 Ezekowitz RA, Sastry K, Bailly P, Warner A. Molecular characterization of the human macrophage mannose receptor: demonstration of multiple carbohydrate 
recognition-like domains and phagocytosis of yeasts in Cos-1 cells. J. Exp. Med. 172(6), 1785-1794 (1990).

160 McGreal EP, Rosas M, Brown GD et al. The carbohydrate-recognition domain of Dectin-2 is a C-type lectin with specificity for high mannose. Glycobiology 16(5), 422-430 (2006).

161 Cambi A, Gijzen K, de Vries JM et al. The C-type lectin DC-SIGN (CD209) is an antigen-uptake receptor for Candida albicans on dendritic cells. Eur. J. Immunol. 33(2), 532-538 (2003).
162 Edwards L, Williams AE, Krieg AM et al. Stimulation via Toll-like receptor 9 reduces Cryptococcus neoformans-induced pulmonary inflammation in an IL-12dependent manner. Eur. J. Immunol. 35(1), 273-281 (2005).

163 Netea MG, Van der Meer JW, Kullberg BJ. Toll-like receptors as an escape mechanism from the host defense. Trends Microbiol. 12(11), 484-488 (2004).

164 Bellocchio S, Gaziano R, Bozza S et al. Liposomal amphotericin B activates antifungal resistance with reduced toxicity by diverting Toll-like receptor signalling from TLR-2 to TLR-4. J. Antimicrob. Chemother. 55(2), 214-222 (2005).

165 Sau K, Mambula SS, Latz E et al. The antifungal drug amphotericin $\mathrm{B}$ promotes inflammatory cytokine release by a Toll-like receptor- and CD14-dependent mechanism. J. Biol. Chem. 278(39), 37561-37568 (2003). 